Abstracta Iranica Abstracta Iranica

Revue bibliographique pour le domaine irano-aryen

Volume 23 | 2002

Comptes rendus des publications de $\mathbf{2 0 0 0}$

\title{
Islam et voyage au Moyen-Age (Histoire et anthropologie d'une pratique lettrée), Paris, Seuil, 2000, 350 p.
}

\section{David Durand-Guédy}

\section{(2) OpenEdition}

10 Journals

Édition électronique

URL : http://journals.openedition.org/abstractairanica/35376

DOI : 10.4000/abstractairanica.35376

ISSN : 1961-960X

\section{Éditeur :}

CNRS (UMR 7528 Mondes iraniens et indiens), Éditions de l'IFRI

\section{Édition imprimée}

Date de publication : 15 mai 2002

ISSN : 0240-8910

\section{Référence électronique}

David Durand-Guédy, «Islam et voyage au Moyen-Age (Histoire et anthropologie d'une pratique lettrée), Paris, Seuil, 2000, 350 p. », Abstracta Iranica [En ligne], Volume $23 \mid 2002$, document 132, mis en ligne le 08 février 2010, consulté le 25 septembre 2020. URL : http://journals.openedition.org/ abstractairanica/35376 ; DOI : https://doi.org/10.4000/abstractairanica.35376

Ce document a été généré automatiquement le 25 septembre 2020.

Tous droits réservés 


\title{
Islam et voyage au Moyen-Age (Histoire et anthropologie d'une pratique lettrée), Paris, Seuil, 2000, 350 p.
}

\author{
David Durand-Guédy
}

1 Houari Touati écrit en ouverture de son livre que « les lettrés du Moyen-Age musulman ont été des forcenés du voyage ». Son étude, qui se place à la croisée de l'histoire et de l'anthropologie, vise à préciser les conditions culturelles et économiques qui permettent de partir : pourquoi et comment le voyage est-il parvenu en islam à s'ériger en geste intellectuel de fondation? Pour cela l'A. s'est limité à l'âge d'or de l'islam $\left(8^{\mathrm{e}}-12^{\mathrm{e}} \mathrm{s}\right.$.), quatre siècles qui séparent la naissance de la riḥla comme "voyage en quête du savoir » de son avènement comme « récit de voyage ».

2 La façon dont Touati problématise les enjeux du voyage rend la lecture de ce livre passionnante. Le premier chapitre par exemple procède d'une réflexion sur la notion de 'ilm pour montrer comment les traditionnistes ont réussi au $8^{\mathrm{e}} \mathrm{s}$. à justifier l'institution du voyage en accréditant l'idée d'une disparition imminente du 'ilm, menacé par l'oubli. Une fois que s'est mise en place la science des haditit-s basée sur l'authenticité des chaînes de garants (isnād) commence une "course après les hautes chaînes ", c'est-à-dire celles qui se rapprochent le plus du Prophète. Dans le même temps, à partir des écoles de lexicographie iraqiennes, se développe un autre voyage, à la recherche non plus du hadịt dans les villes, mais de la langue des Bédouins du désert (fașahāa) qui devient alors un idéal littéraire. L'évolution de la discipline telle que la raconte l'A., d'Abū 'Amrū au $8^{\mathrm{e}} \mathrm{s}$. à Azharī au $10^{\mathrm{e}} \mathrm{s}$. en passant par le célibrissime Asma'ī, est illustrée par de nombreux exemples et permet de dresser une véritable "géographie de la langue pure ». Ces pérégrinations ont évidemment un prix, et un chapitre particulièrement vivant est consacré aux embûches, financières notamment, qui attendent le voyageur. Finalement au $12^{\mathrm{e}} \mathrm{s}$., les moteurs du voyage fondés sur l'audition ont disparu: il est désormais inutile de partir écouter le Bédouin car la langue claire et pure, enfermée dans les livres, fonctionne comme un système clos; quant aux longs séjours à l'étranger auprès des maîtres, ils sont peu à peu vidés de leur 
substance avec le développement de la pratique de l'«ijâza in absentia ». Un deuxième mode de la connaissance existe, non plus fondé sur l'audition (samá) $)$, mais sur le regard ('iyān) : ce mode régit les voyages des géographes chers à André Miquel, qui sont longuement traités dans le quatrième chapitre. Enfin un dernier type de voyage est décrit : celui du soufi, Touati définissant le soufisme comme «traversée du désert ». Au terme de la période envisagée, le voyage devient lui-même objet de récit, et ce sont les caractéristiques de son écriture qu'analyse l'A. à la fin de l'ouvrage.

Le livre fait ainsi le lien entre diverses catégories d'hommes (traditionnistes, géographes, linguistes, soufis) qui jusque-là étaient abordées séparément. Pour sa recherche, l'auteur a utilisé un éventail particulièrement vaste de sources, dont plusieurs manuscrites. Toutes sont en arabe, mais l'Iran, dont l'importance dans l'élaboration de la culture islamique n'est pas niée par l'auteur, est loin d'être négligé : de ZamaHšarī venant au Hijāz pour humer «le parfum des aiguades des authentiques Arabes » aux voyages de Ṭabarī en passant par la quête mystique d'al-Hakīm al-Tirmidî et au journal de voyage composé en arabe par le Șāhịib Ibn 'Abbād, les exemples sont nombreux qui mettent en scène les habitants orientaux d'un monde unifié culturellement et que l'on appelle encore « mamlakat al-islām », l'empire de l'Islam. Un livre stimulant et passionnant.

INDEX

Thèmes : 4.1. Histoire médiévale

\section{AUTEURS}

DAVID DURAND-GUÉDY

IFRI - Téhéran 